\title{
Malignant Salivary Gland Neoplasm
}

National Cancer Institute

\section{Source}

National Cancer Institute. Malignant Salivary Gland Neoplasm. NCI Thesaurus. Code C3811.

A primary or metastatic malignant neoplasm that affects the major or minor salivary glands. Representative examples include carcinoma, lymphoma, and sarcoma. 